Technical Report Documentation Page

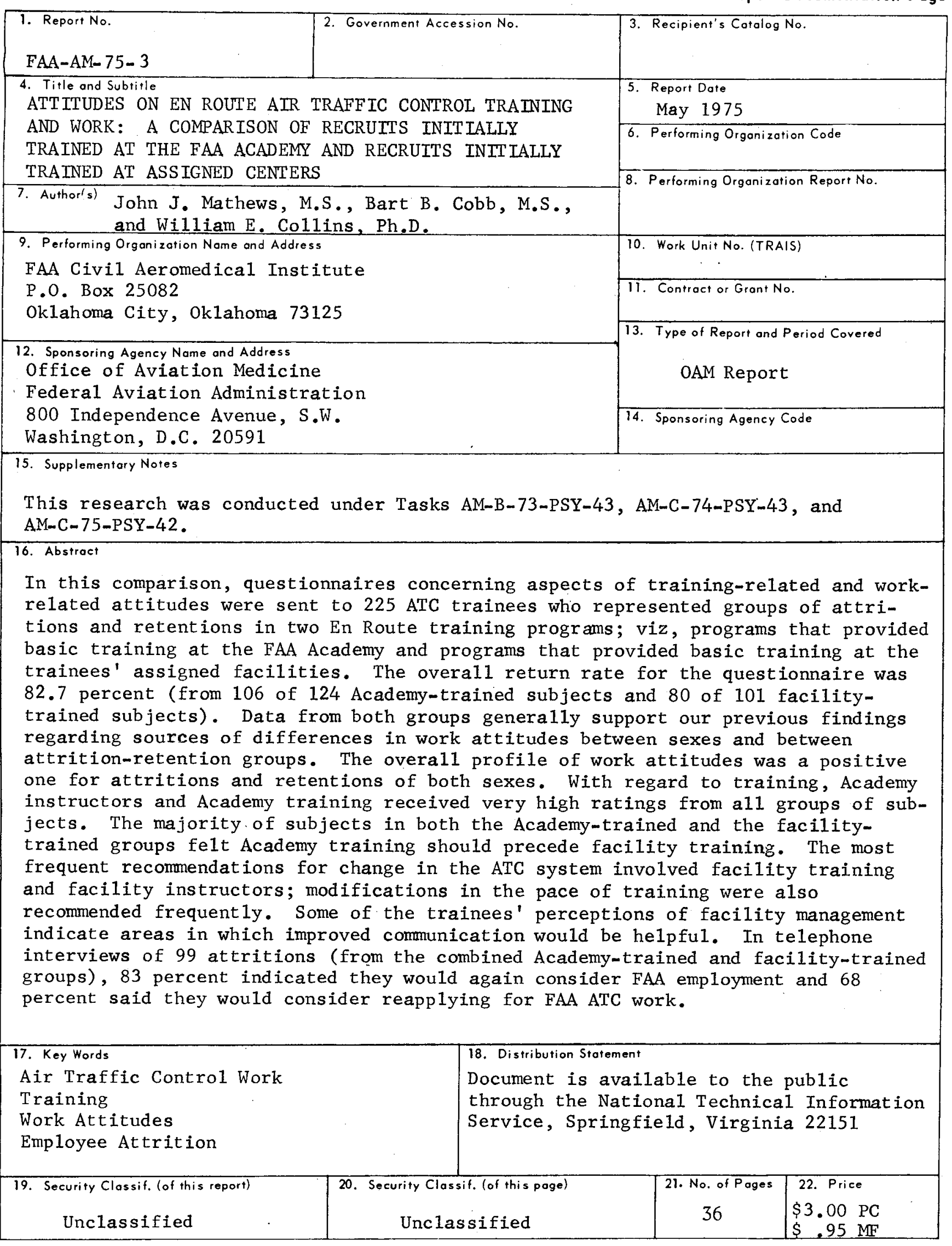

Form DOT F 1700.7 (8-72)

Reproduction of completed page authorized 



\section{ATTITUDES ON EN ROUTE AIR TRAFFIC CONTROL TRAINING AND WORK: A COMPARISON OF RECRUITS INITIALLY TRAINED \\ AT THE FAA ACADEMY AND RECRUITS INITIALLY TRAINED AT ASSIGNED CENTERS}

\section{Introduction.}

Two recent studies of trainee attrition in the Federal Aviation Administration (FAA) air traffic control (ATC) occupation included Flight Service Station (FSS), En Route, and Tower trainees and were concerned with sex differences both in reasons for attrition ${ }^{1}$ and in attitudes toward various aspects of the ATC job. ${ }^{2}$ The present study focuses on attitudes toward ATC training of the En Route subjects who participated in those studies and of another group of subjects who entered En Route training under a different training program

The two attrition studies ${ }^{12}$ previously reported drew subjects from among those trainees who entered the FAA Academy during the period from December 1968 through March 1970. Virtually all of those trainees were sent to the Academy either immediately or within several weeks after being hired. En Route trainees who successfully completed the Academy's 2-month basic training course on air route traffic control procedures were awarded training certificates and then assigned or returned to their air route traffic control centers for subsequent (facility) training; promotion from trainee to jourmeyman status generally requires a minimum of 3 years. In this training sequence, the Academy effectively served as an early screening device (secondary to the qualifying aptitude tests) by eliminating those who failed to satisfactorily complete Academy training (e.g., 21.6 percent of the 1,855 En Route trainees failed to complete Academy training in 1969). ${ }^{3}$

However, En Route trainees recruited after March 1970 received 8 to 14 months of initial

*We gratefully acknowledge assistance in data analysis by Dr. Earl Folk, Steve Greer, Rosalie Melto Peter Nelson, and Barbara Rizzuti. training at their facilities and were then sent to a 2-month advanced course at the Academy (FSS and Tower trainees continued to receive initial training at the Academy throughout 1970 and received most of their advanced training at field facilities). FAA data indicate that only 12 percent of the En Route trainees hired in 1970 were terminated that same year (the vast majority of these trainees did not attend the Academy in 1970). ${ }^{4}$

While differences between these two training approaches raise interesting questions regarding cost/benefit factors of early versus later secondary screening (i.e., assessing during training the probability of a trainee's being successful in ATC work and eliminating those who do not meet the training standards), the present paper was directed toward four major purposes:

1. Assessing the general attitude of En Route hirees toward their ATC training.

2. Assessing possible differences in the attitudes of trainees toward Academy and facility training, depending on whether Academy training preceded or followed facility training.

3. Assessing possible differences in a variety of job attitudes held by trainees, depending on whether Academy training preceded or followed facility training.

4. Assessing possible sex differences and attrition-retention differences in these attitudes.

\section{Method.}

A. Subjects. The data groups for this study comprise a total of 225 men and women who entered En Route ATC training during 1969 and 1970. Of this total, 124 trainees (62 men and 62 women) entered when initial training was given at the Academy and 101 trainees $(65$ men and 36 women) entered when initial training was conducted at the facilities. 
1. Academy-trained group. The subjects composing the group referred to as the Academytrained group represent the 124 En Route trainees from a sample of 238 air traffic control specialists (ATCS) used in previous studies of job attrition. ${ }^{12}$ The procedures used in selecting the sample of 238 (which also included 114 trainees in the Terminal and FSS options) are detailed in one of these studies ${ }^{2}$; the major consideration was to include all women hired during the period under study. Thus, the group of 124 trainees of the present study comprised all 62 women who entered the En Route course at the Academy from December 1968 through March 1970 and also 62 men from the same classes. Each man selected was chosen to match a female counterpart as closely as possible with respect to a number of variables including age, possession of previous certified ATC experience (usually from military service), size and geographical location of the Center facility to which assigned, date of entry into Academy training, duration of employment, and salary. Howerer, the most important of the matching variables was retention-attrition status. Using June 1, 1972, as a cutoff date, we found that 28 women (and, there fore, their 28 male matches) were still in FAA ATC work (retentions) while 34 women (and the matched 34 men) had left ATC work (attritions). Whereas the 62 women represented the entire input of females to the Academy En Route courses during the period, the 62 men represented only a small percentage of male trainees entering during the period. It should be noted that the attrition rate of 55 percent for the women was significantly higher than that (38 percent) ${ }^{3}$ for the total input of trainees. While there was no difference in attrition during Academy training (around 20 percent for each sex), the percentage of women leaving $\mathrm{ATC}$ work during subsequent facility training was about twice that of men.

2. Facility-trained group. All 101 of the En Route trainees in the group referred to as the facility-trained group (a) were hired during the period April-December 19ז0, (b) received initial training at their assigned Centers, and (c) did not attend Academy basic training; this group comprised 36 women and 65 men. Using January 1973 as a cutoff date, we found that 16 of the women and 30 of the men were attritions while 20 women and 35 men were retentions. The 36 women represented all the females hired during the time period under study. Each woman was matched with a man having the same attrition-retention status and the same factors noted above for Academy-trained personnel. Additional male subjects (14 attritions and 15 retentions) were added to increase the overall size of the test sample.

B. Procedure. Biographical data concerning the subjects and their work settings were obtained from several sources with overlapping data providing reliability checks. On entry into Academy training, each subject completed a personal background and data sheet by providing birth date, education, previous work experience, date of employment, type of training option, and facility to which initially assigned. Personnel records maintained at FAA Headquarters were used to determine whether subjects were still in ATC work, to verify types and facilities of assignment, and to obtain dates of separation of those ATCS's no longer with the FAA.

Attritions were contacted by telephone and given a semi-structured interview ${ }^{1}$ in which they were asked their primary and secondary (if any) reasons for leaving ATC work, their present marital status and number of children, if they were currently working or in school, and if they would consider returning to the FAA and ATC work. They were then informed that a questionnaire (Appendix A) about some aspects of their ATC experience would be mailed to them for completion. Retentions were also sent a copy of the questionnaire along with an explanatory letter asking for their help and cooperation.

C. The Questionnaire.

1. Section A. Section A of the six-part Air Traffic Control Trainee Questionnaire concerned 10 job-related factors and included from 4 to 16 agree-disagree items for a given factor; the total number of items was 107 . Seven of the factors are aspects of the work environment (work itself, supervision, coworkers, pay, promotions, management, and working conditions) that have been reported as relating to job satisfaction and motivation. ${ }^{6} 78$ The other three are sources of attitudinal differences that might exist in ATC work; namely, assignments (geographical and type of control work), facility training, and shift work. Approximately the same numbers of positively and negatively worded items were derised to minimize response set tendencies. 
2. Section B. Section B consisted of two freeresponse, or open-ended, statements for elicitation of what each subject regarded as the best and worst features of being an FAA air traffic controller. The responses were sorted into 16 categories, corresponding to those specified by Herzberg. ${ }^{9}$ Six of the factors, designed by Herzberg as "motivators" and primarily associated with job satisfaction, are: worls itself, achievement, responsibility, recognition, advancement opportunity, and possibility of growth. The remaining 10 factors, concerning hygiene (i.e. work situations) and usually associated with job dissatisfaction, are: company policy and administration, working conditions, technical supervision, interpersonal relations with peers, factors in personal life, salary, interpersonal relations with superiors, job security, status, and interpersonal relations with subordinates.

3. Section C. The 11 items in Section C measured, on a 5-point scale, (a) how well informed the subject felt he or she was about four aspects of the job upon accepting appointment to ATC work (i.e., job duties, career progression, opportunities for transfer to non-ATC jobs, and the "how" and "when" of possible elimination from training) and (b) how he or she viewed seven aspects of ATC training. The latter included evaluating facility training, Academy training, facility instructors, Academy instructors, the ability of Academy instructors to predict which trainees were likely to be good or poor at ATC work, the subject's degree of understanding of ATC work, and the subject's ability to apply that understanding as a result of Academy training and as a result of facility training. Rating choices ranged from "excellent" (code 5) through "neither good nor bad" (code 3) to "very bad" (code 1).

4. Section D. In Section D, each subject was asked to suggest two changes for the ATC system. Each suggestion was placed in one of several categories (e.g., training suggestions), which were established after sorting through all suggestions.

5. Section E. Section E (16 items) elicited responses involving perceived attitudes of management, supervisors, and journeyman controllers toward trainees based on sex, age, minority membership, and trainee status in general. This section consisted of four parts, and each part comprised four items. In the first part, the sub- ject was asked to indicate how much, in terms of job duties, he or she felt was expected of each of four training groups (i.e., females, minority members, older trainees, and all newly hired ATCS's) by the supervisors or crew chiefs. The five response alternatives ranged from "much more than should be" (coded as 5) to "much less than should be" (coded as 1). The second part consisted of a similar group of items but pertained to the subject's concept of the expectations of journeyman ATCS's rather than of supervisory personnel. In the third part, the subject was asked about how he or she thought the journeyman controllers generally accept each of the four trainee groups; the five response alternatives ranged from "completely accept" to "completely reject." The fourth part concerned the general treatment of each of the four trainee groups by journeymen; five choices, ranging from "very good" to "very bad," were offered. For analytic purposes, responses to items of the third and fourth parts were assigned codes of 1 to 5 ; in each instance, the lowest code pertained to the most negative view and the highest reflected the most positive view.

6. Section F. Questionnaires mailed to the attrited subjects only included an additional section (i.e., Section F), listing 20 possible reasons for leaving ATC work. Space was allocated beside most of the 20 items for giving more detailed information or examples. The respondent was asked to indicate, in rank order, one to four reasons bearing upon a decision to terminate FAA ATC employment. Although some subjects ranked more than four causes for termination, those ranked beyond the fourth were ignored for analysis purposes. On the basis of trends in responses, a few alternatives were grouped; the few that elicited no responses were eliminated. For the telephone interviews, three raters, in cluding one of the authors (JJM), separately categorized the reasons for attrition, noting a main reason and, if given, one to three secondary reasons. If two or all three of the raters agreed on the main reason, that became the consensus in the few cases in which all raters disagreed, the consensus reason was chosen by one of the authors (JJM).

D. Response Rate. As mentioned earlier, 34 of the 62 females and also 34 of the matched group of 62 males recruited prior to discontin- 
As mentioned earlier, the 30 facility-trained male attritions included 25 who participated in the telephone interviews, whereas only 10 of the 16 facility-trained female attritions were interviewed. Some 28 percent $(N=7)$ of the 25 males claimed to have left because of training difficulties and the same proportion cited other job opportunities, 16 percent $(\mathrm{N}=4)$ of the males presumably left due to job pressure (responsibility), 12 percent $(\mathrm{N}=3)$ indicated their termination was prompted by policies precluding a transfer to either Terminal or FSS work, and 8 percent $(\mathrm{N}=2)$ cited perceived discrimination. Ten percent $(\mathrm{N}=1)$ of the 10 facility-trained female attritions alluded to problems in training, 30 percent $(\mathrm{N}=3)$ of the 10 cited family-related reasons, 20 percent $(\mathrm{N}=2)$ mentioned job pressure or responsibility, a similar proportion claimed sex discrimination by instructors and coworkers, 10 percent $(\mathrm{N}=1)$ cited another job opportunity, and the one remaining female claimed termination was due to inability to transfer to another A'TC option.

Results from the two training groups are similar with regard to the major reason for attrition other than training difficulties; namely, another job for men and family reasons for women. However, there are also some interesting differences between the groups. First, the number citing training failures or difficulties is smaller for both men and women who did not attend basic training at the Academy. Since the Academy, in addition to training, provided a screening function, this difference is to be expected. As a result of this reduction in training failures among the facility-trained group, other categories, therefore, show increases in the frequency with which they were cited as reasons for attrition. 'Thus, in the case of men, another job opportunity and job pressure showed the highest gains. For women, family reasons for attrition remained about the same (30 percent) while every category other than miscellaneous - increased somewhat. It is of interest that (a) reasons for attrition associated with job pressure increased for both men and women who were facility trained, (b) family reasons were stable (and high) for women in both groups, and (c) the importance of another job opportunity as the major non-training-related reason for male attritions was affirmed. ${ }^{1}$
2. Reasons for attrition obtained from Section $F$ of the questionnaire. The frequency of reasons for attrition cited on Section $F$ of the questionnaire appear in Table 2. Both Academy-trained and facility-trained women cited family problems most frequently ( 25 percent for each group) and training failures second (21 percent and 17 percent). Some form of perceived discrimination (17 percent) and inadequate training (13 percent) were also cited by Academy-trained women but were not mentioned as frequently by facilitytrained women. Among the men, both Academytrained and facility-trained attritions cited training failure and inadequate training as the two primary reasons for leaving ATC work; no other single reason for either group accounted for as much as 10 percent of the responses. These results generally are similar to those obtained from the telephone interviews. A comparative analysis of differences between the categories of reasons for attrition obtained from telephone interviews, questionnaires, and job-exit forms has already been presented elsewhere. ${ }^{1}$

B. Section A of the Questionnaire: Job Attitudes.

1. General findings. To assess the degree of "favorableness toward" or "satisfaction with" each aspect of work, the percentage of subjects agreeing to positively worded items and disagreeing to negatively worded items in Section A was calculated. Based on these calculations, the percentages of the total group expressing favorable attitudes ranged from 14 percent (for "good opportunity to transfer assignments") to 98 percent (for two items: neither coworkers nor supervisors were viewed as overly protective). The average favorableness for all 107 items was 68 percent (Table 3; also see Appendixes C, D, and E). The percentages were almost identical for the Academy-trained and facility-trained groups (69 and 68 percent, respectively).

Twelve items were answered positively by more than 90 percent of the Academy-trained, facility-trained, or combined groups of subjects. All groups agreed that ATC work was respected and challenging, that supervisors were not overly protective, and that coworkers were neither overly friendly nor overly protective. Coworkers were seen as responsible by 95 percent of the Academy-trained group and by 89 percent of the facility-trained group. Similarly, 91 percent and 


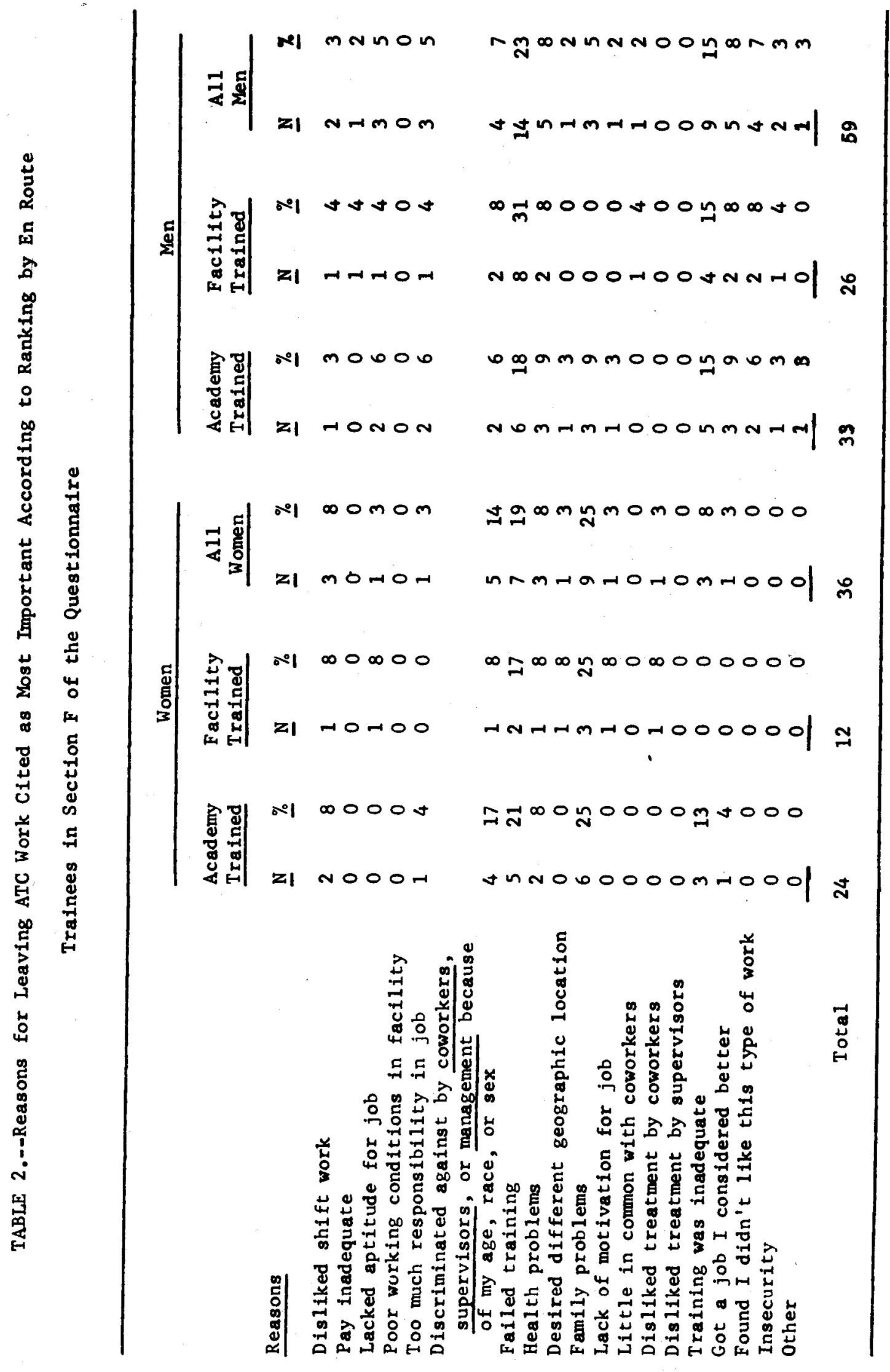


treated them differently; that they were harassed more than most others during facility training, which in itself was seen as too hurried and not adequate; that they had less often been assigned to the option or the facility they wanted; and that they less often saw shift length as O.K. and the ATC work itself as fascinating or pleasant. Retentions agreed more often than attritions that they were not highly paid, that shift work made it hard to manage outside responsibilities, that promotions were limited and infrequent, that equipment was not up to date, and that facility management did not exhibit good planning.

C. Section $B$ of the Questionnaire: Features of the Job. In Section B, subjects were asked to state the best feature and the worst feature of being an ATCS. Of the Academy-trained subjects who returned questionnaires, 19 of the $25 \mathrm{fe}-$ male attritions, 29 of the 33 male attritions, and 21 each of the 29 male and 24 female retentions cited a best feature; a worst feature was stated by 17 female and 21 male retentions and by 15 female and 29 male attritions. Among the facilitytrained subjects who returned questionnaires, a best feature was cited by 11 of 12 female and 25 of 26 male attritions and by all 13 female and all 29 male retentions; a worst feature was stated by 12 female and 22 male attritions and by $13 \mathrm{fe}$ male and 29 male retentions (see Table 4).

Of the categories, which correspond to those used by Herzberg, ${ }^{9}$ salary (30 percent versus 44 percent), work itself (19 percent versus 12 percent), and achievement (18 percent versus 26 percent) accounted for the majority of features cited as best about ATC work for the Academytrained and facility-trained groups, respectively. The Academy-trained group also frequently cited job security (13 percent) and recognition (11 percent). Working conditions (41 percent versus 29 percent) and company policies and administration (22 percent versus 17 percent) were the two worst features mentioned primarily by the Academy-trained and facility-trained groups, respectively. The latter group also frequently cited responsibility (17 percent) and job security (13 percent) as a worst feature, while 10 percent of the Academy-trained group cited peer relationships as a worst feature. No other categories comprised as much as 10 percent of the responses.

In general, for both groups, two of the three most frequently cited best features (work itself and achievement) are the same as those noted by
Herzberg as top motivator factors, and two of the three most frequently cited worst features (company policies and working conditions) are identical with Herzberg's top hygiene factors. Salary is mentioned as a best feature more often by FAA controllers than by many other occupational groups ${ }^{10}{ }^{11}$; this incidence is probably related to the fact that pay is relatively high for the ATC entry-level experience and education requirements (but not necessarily for the responsibility and mental abilities involved). This appears particularly true for En Route trainees (who tend to be higher paid than FSS and Tower personnel), but its high rank in this study, compared with its relatively lower ranking in other studies, ${ }^{10} 11$ may be due to the way the question was phrased; e.g., citing the best feature of being a controller versus citing what the trainee likes best about ATC work. Responsibility, usually a motivating factor, was a relatively high-ranking worst feature, especially for the facility-trained group. In view of the critical role controllers have in the safety of air passengers, some apprehension conceming their responsibility is understandable.

In comparing attritions and retentions, we found a remarkably high degree of similarity in the proportions of subjects who cited the various categories of best and worst features of ATC work (Appendix F). Similarly, only one major difference appeared in comparing the features reported by men and women (Appendix F); viz, men more often than women listed job security as a worst feature (15 percent versus 4 percent, $p<0.05$ by chi square)

D. Section $C$ of the Questionnaire: Orientation and Training.

1. Information about the ATC career at time of appointment. There were no significant differences between men and women (Appendix G), between attritions and retentions, or between the Academy-trained and facility-trained groups on any of the four items dealing with the quality of information they received about the ATCS career at the time of their appointment. For both training groups, average ratings for three items (knowledge about (a) ATC job duties, (b) the "how and when" of elimination from training, and (c) career progression) were near the midpoint on the 5-point scale (total group means ranged from 2.80 to 3.37 ) ; i.e., near 3 , where the 


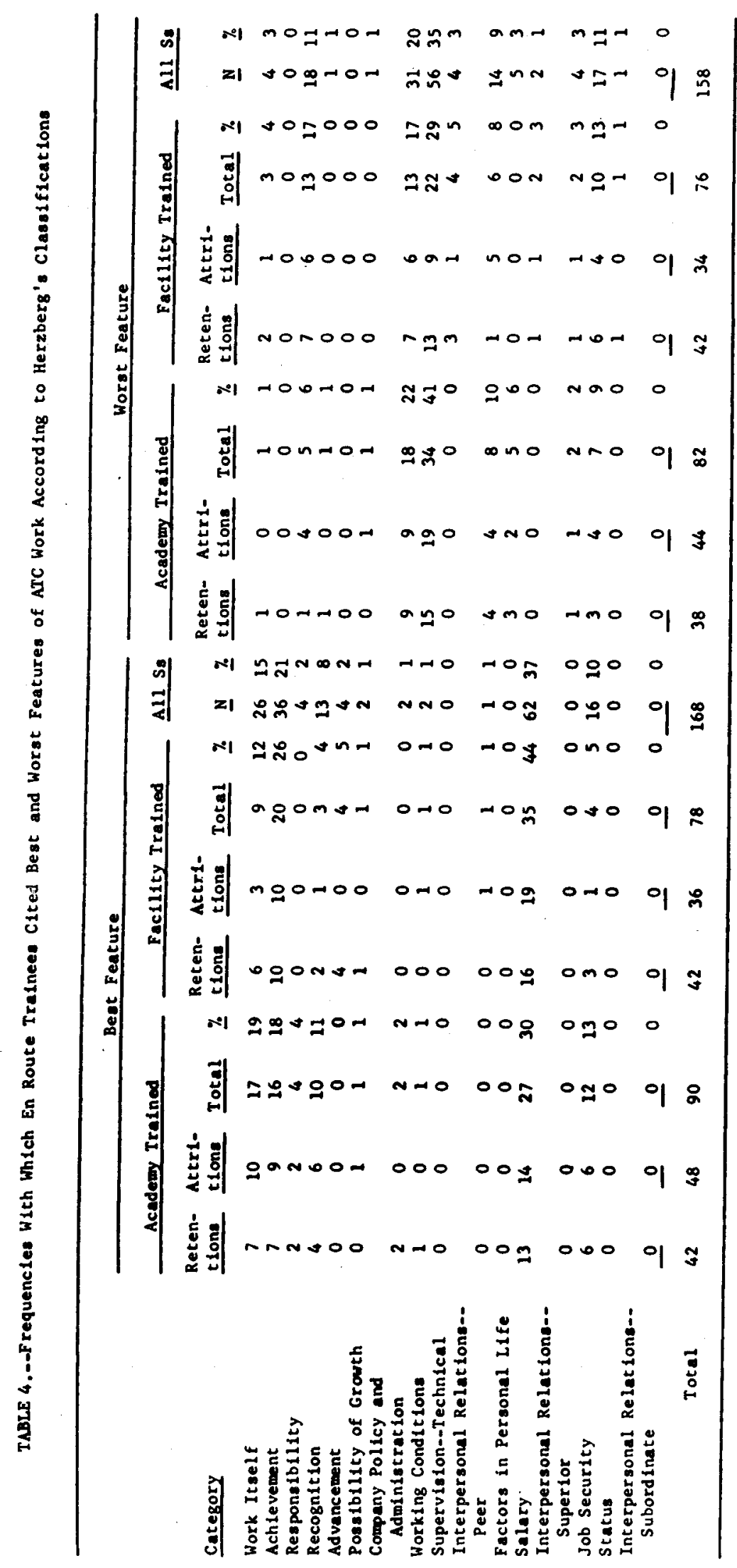


TABLE 5. --Frequencies with Which Categorized Recoumendations Concerning Changes in the ATC System Were Suggested by En Route Trainees in Section D of the Questionnaire

\begin{tabular}{|c|c|c|c|c|c|c|c|c|c|c|}
\hline \multirow{2}{*}{$\begin{array}{l}\text { Recommend at ions } \\
\text { concerning: }\end{array}$} & \multicolumn{4}{|c|}{ Academy Trained } & \multicolumn{4}{|c|}{ Facility Trained } & \multicolumn{2}{|c|}{ A11 Ss } \\
\hline & $\begin{array}{l}\text { Reten- } \\
\text { t1ons } \\
\end{array}$ & $\begin{array}{l}\text { Attri- } \\
\text { tions } \\
\end{array}$ & Total & \% & $\begin{array}{l}\text { Reten- } \\
\text { tions } \\
\end{array}$ & $\begin{array}{l}\text { Attri- } \\
\text { tions } \\
\end{array}$ & Tota1 & $\underline{\%}$ & $\mathbf{N}$ & $\underline{\%}$ \\
\hline Training & 19 & 43 & 62 & 34 & 31 & 29 & 60 & 44 & 122 & 38 \\
\hline Management & 14 & 14 & 28 & 16 & 11 & 3 & 14 & 10 & 42 & 13 \\
\hline Work Itself & 6 & 8 & 14 & 8 & 7 & 6 & 13 & 10 & 27 & 9 \\
\hline ATCS selection & 12 & 5 & 17 & 9 & 2 & 4 & 6 & 4 & 23 & 7 \\
\hline Work schedule & 5 & 4 & 9 & 5 & 5 & 8 & 13 & 10 & 22 & 7 \\
\hline Trang fers & 6 & 3 & 9 & 5 & 3 & 4 & 7 & 5 & 16 & 5 \\
\hline Promotions & 7 & 3 & 10 & 6 & 3 & 2 & 5 & 4 & 15 & 5 \\
\hline Equipment & 4 & 4 & 8 & 4 & 5 & 1 & 6 & 4 & 14 & 4 \\
\hline Discrimination & 4 & 3 & 7 & 4 & 0 & 3 & 3 & 2 & 10 & 3 \\
\hline Miscellaneous & 7 & 10 & 17 & 9 & 4 & 5 & 9 & 7 & 26 & 8 \\
\hline Total & 84 & 97 & 181 & & 71 & 65 & 136 & & 317 & \\
\hline
\end{tabular}

E Section D of the Questionnaire: Suggested Changes. Of the 186 respondents to the questionnaire, the majority complied with the request in Section D for two suggested changes in the ATC system; however, sereral trainees submitted none and a few only one. The 58 attritions of the Academy-trained group who returned questionnaires provided a total of 97 recommendations (rather than 116), reflecting a relative response rate of 83.6 percent; the corresponding rate for the retentions was 87.5 percent. Of the facility-trained trainees, the response rates were 85.5 percent for the attritions and 84.5 percent for the retentions.

Of the total of 317 changes suggested for the ATC system (Table 5), most concerned ATC training ( 38 percent of all recommendations) and management (13 percent). Aspects of the work itself were the object of 9 percent of the recommendations, followed by miscellaneous suggestions ( 8 percent), ATCS selection standards ( 7 percent), work schedule ( 7 percent), transfers (5 percent), promotions ( 5 percent), equipment (4 percent), and perceired discrimination (3 $(4$ percent), and perceived discrimination
percent). Although all of the suggestions deal- ing with discrimination were made by women (four retentions and six attritions), sex discrimination against women was mentioned less than special farors granted to "minority" groups, which include women.

Overall, of the 122 suggestions specifically mentioning training, 27 percent were general in nature, 24 percent criticized the pace of training, 17 percent pertained to improving facility training, and 16 percent suggested changes concerning the selection and training of facility instructors (Appendix I). Many of the 42 recommendations involving management reflected a perceived "up or out" or "feast or famine" policy; i.e., perceptions that trainees either advanced to journeyman level after a specified amount of training or were eliminated from the air traffic system due to very limited opportunities for transfers (either to other types or levels of facilities or to other series of FAA jobs). A number of comments supplementing these recommendations alleged a negative attitude and a lack of concern for people on the part of ATC management. 
There were no differences between the Academy-trained and facility-trained groups or between men and women in the frequencies of any of the categorized recommendations. When retentions and attritions were compared, attritions gave significantly more responses $(p<0.05$ or better by chi square) concerning ATC training (46 percent versus 32 percent) and fewer responses regarding management ( 8 percent versus 18 percent).

F. Section E of the Questionnaire: Perceived Status of Trainees. This section comprised four subsections, each of which- included four items. The items pertained to expectations, acceptance, and treatment of four groups of trainees (viz new trainees in general, women, minorities, and trainees over 35 years of age). The Academytrained and facility-trained groups differed significantly (by t test) on only one of the 16 items the expectations of supervisors for new trainees in general was rated higher by the Academy. trained group (3.19 versus 3.00). It should be noted, however, that both means are close to ratings of "about what should be" (see Figure 3).

For both groups, the ratings for expectations held by supervisors are "about what should be" for new trainees in general and for older trainees; the supervisors' expectations for these subgroups received the highest ratings (Figure 3 ). Lower ratings were given to supervisors' expectations of performance by women (2.96 and 2.75 by the Academy-trained and facility-trained groups, respectively) and by minorities (2.87 and 2.64). The ratings of women and minorities (particularly the latter) by the facility-trained croup clearly fall between the categories of "less than should be" to "about what should be."

The rating patterns for both the Academytrained and facility-trained groups regarding the expectations held by journeyman controllers were similar in that the highest ratings were recorded for all new trainees in general and for older

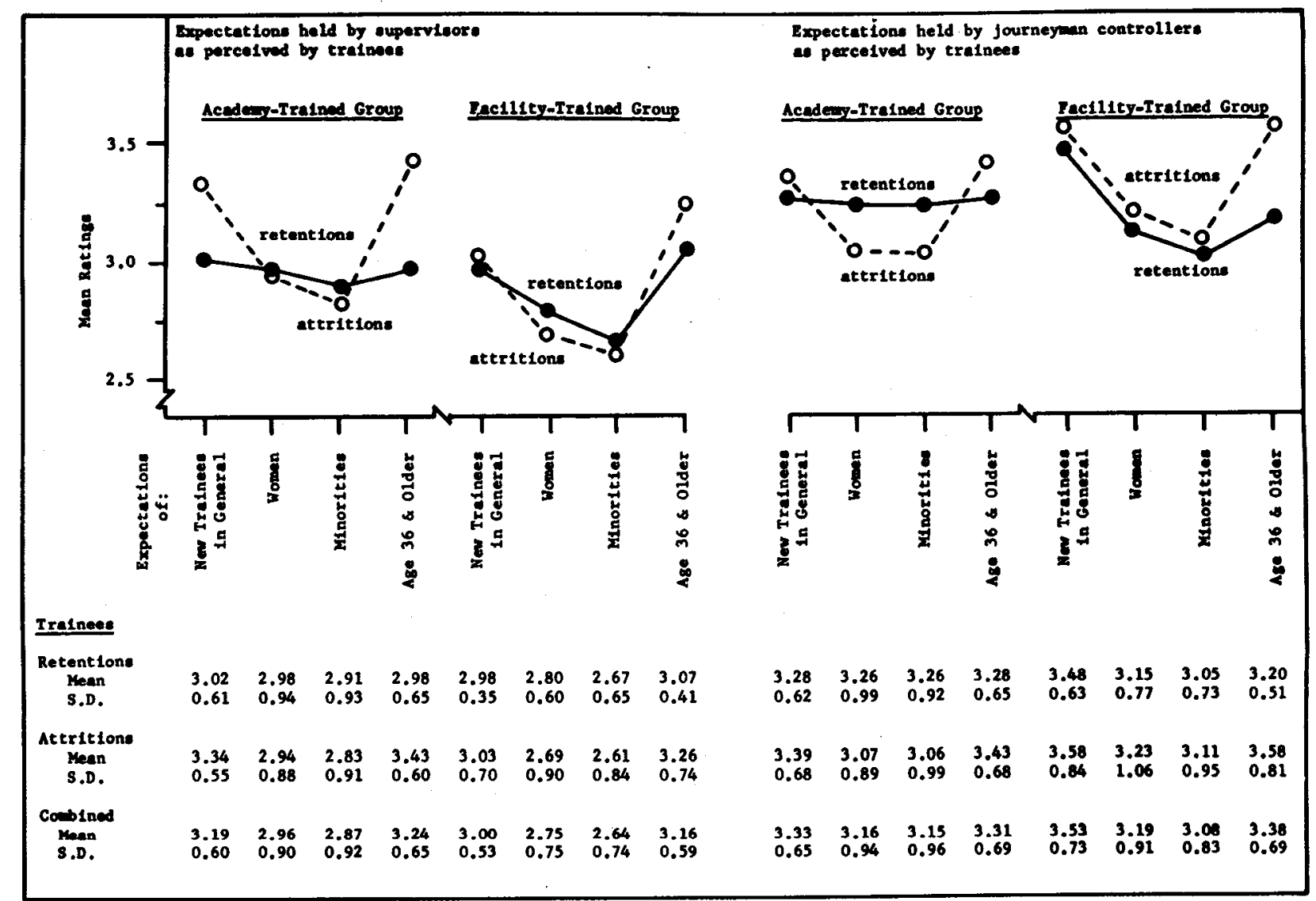

FIGURE 3. Mean ratings by En Route recruits of their perceptions of supervisory and journeyman controllers' expectations of trainees (in response to Section $\mathbf{E}$ of the questionnaire). 


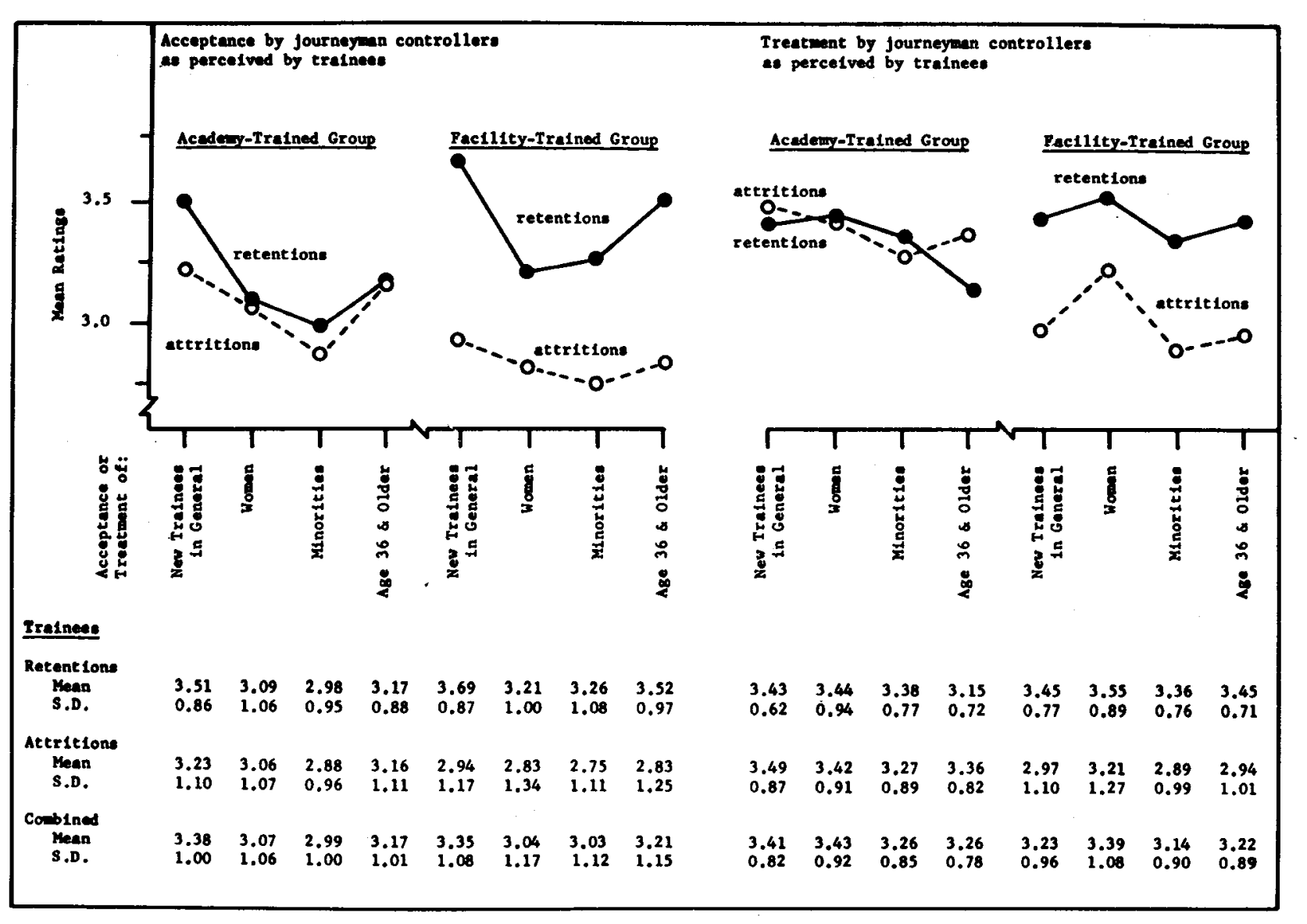

FIGURE 4. Mean ratings by En Route recruits of their perceptions of journeyman controllers' acceptance and treatment of trainees (in response to Section $\mathrm{F}$ of the questionnaire).

trainees. Relatively lower ratings were given in reference to women, and the lowest ratings pertained to minorities. However, for this subsection, all mean ratings were above 3.00 (i.e., expectations "about what should be"), the range being 3.08 to 3.53 (Figure 3 ).

Regarding both acceptance by and treatment by journeyman controllers (Figure 4 ), all mean ratings for the subgroups were near the neutral code 3 (from 2.99 to 3.43 ), which corresponds to perceptions falling between "neither accept nor reject" and "partly accept" in the one instance and treatment between "neither good nor bad" and "good" in the other.

1. Attritions versus retentions. Only 3 of 16 differences were significant (by t test) between attritions and retentions regarding expectations held by supervisors or by journeyman controllers for the four subgroups (Figure 3). Specifically, the Academy-trained group of attritions rated supervisors' expectations of new trainees in gen- eral and of older trainees significantly higher ( $p<0.01$ in both cases) than did retentions (3.34 versus 3.02 and 3.43 versus 2.98 , respectively), while facility-trained attritions rated the expectations of journeyman controllers significantly higher $(p<0.05)$ regarding older trainees than did retentions (3.58 versus 3.20 ).

Insofar as acceptance and treatment of trainee groups by journeyman controllers is concerned (Figure 4), there were no attrition-retention differences among Academy-trained subjects. Among the facility-trained, however, attritions ranked significantly lower than did retentions both the acceptance $(p<0.05$ to $p<0.01)$ and the treatment $(p<0.05$ in all cases) accorded new trainees in general, minorities, and older trainees. Acceptance and treatment of women were also rated lower, but not significantly so.

2. Males versus females. With regard to expectations held by both supervisors and journeyman controllers, $t$ tests yielded one consistent sex difference (Appendix J). Academy-trained and 
facility-trained women rated significantly higher than did men the expectations for female trainees by supervisors $(p<0.01$ and $p<0.05$, respectively) and by journeyman controllers $(p<0.01$ for both groups). In addition, Academy-trained women rated the expectations of minorities by supervisors significantly higher than did Academy-trained men $(p<0.01)$.

Acceptance by journeyman controllers (Appendix $\mathrm{K}$ ) showed only one sex difference; viz women in the Academy-trained group rated significantly higher than did men (3.60 versus 3.18 , $p<0.05)$ the acceptance of new trainees in general. The treatment accorded the subgroups of trainees yielded two sex differences, both in the facility-trained group; women rated the treatment of both females $(3.65$ versus $2.83, p<0.01$ ) and minorities $(3.28$ versus $2.83, p<0.05$ ) lower than did men.

\section{G. Overview.}

1. Positive features. The feature perceived as best about ATC work was salary (37 percent of the responses to Section B of the questionnaire) Next in frequency were achievement (21 percent) and work itself (15 percent). These best features were classified according to Herzberg's "motivator" categories, and the results were gen erally similar to those reported by Herzberg for other occupational groups. The major difference was that salary, instead of work itself or achieve ment, was chosen as the best feature of ATC work by En Route trainees. However, in response to agree-disagree items in Section A of the questionnaire, more than 90 percent of the subjects said ATC work was useful, challenging and respected. Three-quarters or more of both the Academy-trained and facility-trained subjects perceived their coworkers as responsible and described their work as not boring and as giving them a sense of accomplishment. Similarly, facility management was not seen as discriminatory, overly protective, or setting different standards for trainees. Academy training and Academy instructors received very high ratings from both groups of trainees. Moreover, of the attritions who responded to the telephone interviews (39 women and 60 men), 87 percent of the women and 82 percent of the men not only stated that they would again consider FAA employment, but a clear majority ( $i t$ percent of the women and 65 percent of the men) indicated that they would again consider reapplying for FAA ATC work (although several of the attritions specified the FSS option only). 'Taken in a total context, these findings support our previous reconter attitudes port $^{2}$ that the overall profile of work attitudes is a positive one for attritions and retentions of both sexes.

2. Attrition. The reason most frequently given by En Route attritions for leaving the ATC occupation before reaching journeyman status directly concerned training. In 31 percent of telephone interviews and 36 percent of mail questionnaires, training failure or difficulty (including inadequate training) was mentioned as che from FAA ATC the main reason for attrition from FAA ATC work. Those proportions may even be conservative estimates of the overall percentage of attritions that resulted from training problems, since some distortion might result from orienting selfreported reasons toward social acceptability as well as objectivity. In addition, women were greatly and purposefully overrepresented in the simple ( 44 percent of the sample compared to less than 5 percent of all hirees) for comparative purposes. Nevertheless, approximately one-third of the women in the Academy-trained and facility-trained groups gave family-related reasons for attrition; only 5 percent of the men gave such reasons, but more men than women cited another job opportunity as a cause of attrition. These data support our previous findings regarding causes of ITC trainee attrition and serve to underline the recommendations made in that regard. ${ }^{1}$ However, since the facility-trained subjects were less liable to attrition for training reasons than were Academy-trained subjects, the frequency with which other reasons (unrelated to training) were cited increased. As a result, the third leading reason for attritions of both men and women in the facility-trained group was cited as job pressure.

3. Attrition-retention differences. Most differences between En Route retentions and attritions found in the present study are similar to those cited in a previous report that dealt with Academy-trained subjects of all A'TC options com bined. ${ }^{2}$ Thus, ATC training (particularly that received at field facilities) was generally rated lower by attritions than by retentions (based on replies given in Sections $A, C$, and $D$ of the questionnaire). While the majority of subjects from all subgroujs were positive towards facility 
management and supervisors, attritions provided less positive responses than did retentions. Attritions indicated significantly more often than did retentions that management treated them differently and was not sufficiently capable and that supervisors treated them differently, were hard to please, were annoying, and were not helpful. The report of the previous study" cited several suggestions regarding ways to improve retention rates.

4. Sex differences. The majority of the overall sex differences obtained in this study were also noted in the previous report. ${ }^{2}$ Women were substantially more positive than were men regarding ATC pay. Coworkers (both trainees and journeyman controllers) were viewed considerably more negatively by women than by men ( $\mathrm{Sec}$ tions $\mathrm{A}$ and $\mathrm{E}$ of the questionnaire). Thirty percent of the women compared to 6 percent of the men $(p<0.01)$ agreed that coworkers discriminated against them (Section $\mathbf{A}$ of the questionnaire). Significantly more women than me also felt that coworkers were boring, vulgar, and too friendly. Women responded substantially more often than did men that management and supervisors treated them differently. In addition, supervisors and journeymen were seen by significantly more women than men as expecting more from female trainees than they should. Suggestions offered previously? to improve these attitudes are applicable to the present data.

5. Training needs. Section A of the questionnaire included some items concerning facility training. One item inquired whether Academy training should precede facility iraining. Seventy-one percent of all subjects responding agreed it should. Seventy-nine percent of those initially trained at the FAA Academy agreed Academy training should come first, compare to 62 percent of those initially trained at field facilities $(p<0.05)$. From another perspective 79 percent of the Academy-trained group favored the program alternative under which they were being trained, while only 38 percent of the fa cility-trained group favored the program they were undergoing.

In Section C of the questionnaire, the subjects rated overall Academy training and the ability of Academy instructors as "good" (about 4 on a 5 -point scale) but rated facility training and instructors significantly lower (from one-half to two-thirds of a point). These findings were con- sistent for both the Academy-trained and facility-trained groups. Also, attritions from each group rated their understanding of and ability to apply the training obtained at facilities about one-half point lower $(p<0.05)$ than did retentions.

More of the recommendations listed in response to Section $D$ of the questionnaire concerned training than any other job aspect categorized. This was true for both retentions and attritions of the Academy-trained and facility-trained groups. Thirty-eight percent of the suggestions dealt with training and 13 percent were directed at management. No other area received as much as 10 percent of the recommendations. Of the 122 training suggestions, 33 percent specifically mentioned changes involving either facility training ( 17 percent) or facility instructors (16 percent), and about 8 percent involved either Academy training (5 percent) or Academy in structors (3 percent). Retentions and attritions of each training group recommended more changes for the facility phase of training than for the Academy phase. Seventeen percent of the training suggestions criticized the pace of training (as irregular, too fast, or too slow) Most of the other recommendations (27 percent) were too general to subcategorize or were infrequently cited (miscellaneous).

Despite the frequency of recommendations directed at training, it was not seen as the worst feature of ATC work. In Section B of the questionnaire, 35 percent of the subjects' responses concerning the worst feature were classified under the heading of working conditions. This category includes such aspects of work setting as facilities, work schedule, equipment, and location. The second most disliked feature of ATC work was agency policy and administration (20 percent).

The subject of transfers appears in several sections of the questionnaire. Concerning assignments, only 14 percent of the trainees agreed there was good opportunity to transfer; this was the most unfavorable response to any of the 107 items in Section A of the questionnaire. In Section $C$, the trainees were asked to rate the quality of information they received when hired concerning opportunities to transfer to non-ATC jobs. In this regard, the mean ratings of the various groups ranged from 1.94 to 2.14 on the 5-point scale wherein "2" represented "bad." 
H. Training Implications. Although some changes may have been instituted in the ATC training programs in the interim between our collection of data and the writing of this report, the findings detailed in this study provide several types of information about En Route training. These include feedback on the trainees' evaluations of ATC training, the morale of trainees who are retentions, the perceptions of eliminated trainees concerning why they are no longer in FAA ATC work, and the comparative attitudes of male and female trainees. In light of this information from the trainees' standpoint, what can be done to improve the En Route training situation?

1. Improve initial orientation to the ATC career regarding the nature, demands, and rewards of ATC work. Particularly improve orientation with respect to the limited possibilities of transferring both within ATC options and from ATC to other types of work. Also, promotional opportunities should be clearly defined.

2. Introduce Academy courses relatively early in the training phase.

3. Use the Academy instructors to fullest ad vantage in identifying trainees who need addi- tional help and, in at least some cases, in recommending facility assignments (see also Office of Aviation Medicine Report No. 74-1012).

4. Emphasize training ability in the selection of facility instructors.

5. Train instructors with regard to fair treatment of all trainees, motivational techniques in instruction, and the psychology of both the teaching and the learning processes.

6. Alert supervisors to the importance of praising the individual trainee for good work.

7. Eliminate irregularities in the pace of training.

8. Emphasize achievement and cooperation among trainees rather than competition.

9. Increase opportunities for transferring both within ATC options and from ATC to other types of work as alternatives to elimination from ATC training.

10. Improve trainees' understanding of management policies and practices in the facilities.

11. Increase the opportunities for contact between trainees and facility management, with greater emphasis directed toward the understanding and acknowledgment by facility management of communications from trainees.

\section{REFERENCES}

1. Mathews, J. J., W. E. Collins, and B. B. Cobb: A Sex Comparison of Reasons for Attrition of NonJourneyman FAA Air 'Traffic Controllers. FAA Office of Aviation Medicine Report No. AMI-74-2, 1974. .

2. Mathews, J. J., W. E. Collins, and 13. 13. Cobb. JobRelated Attitudes of Non-Journeyman FAA Air Traffic Controllers and Former controllers: A Sex Comparison. FAA Office of Aviation Medicine Report No. AM-74-7, 1974

3. Cobb, B. B., J. J. Mathews, and P. I. Nelson: Attrition-Retention Rates of Air Traftic Control Trainees Recruited During 1960-1963 and 1968-1970. FAA Office of Aviation Medicine Report No. AMI-72-33, 1972.

4. Farrell, R. A.: Air Traffic Control Specialist AttriFirom AMN-23 to tion, Official Fareh $31,1972$.

AAC-118, March 31, 1972.
5. Cobb, B. B., J. J. Mathews, and C. D. Lay: A Com

5. Cobb, B. B., J. J. Mathews, and C. D. Lay: A Com troller Trainees. FAA Office of Aviation Medicin Report No. AM-72-22, 1972.

6. Hoppock, R.: Job Satisfaction. New York, Harper and Brothers, 1935.

7. Herzberg, F. : One More Time: How Do you Motivate Employees? HARVARD BUSINESS REVIEW $46: 53-62,1968$

8. Smith, P. C.: The Development of a Method of Measuring Job Satisfaction: The Cornell Studies. In E. A. Fleishman (Ed.), Studics in Personnel and Industrial psychology, Homewood, Illinois, Dorsey, 1969.

9. Herzberg, F.: Work and the Nature of Man, New York, World Publishing Company, 1966.

10. Smith, R. C., B. B. Cobb, and W. E. Collins: Attitudes and Motivational Factors in Terminal Area Air Traffic Control Work FAA Office of Aviation Medicine Report No. AM-71-30, 1971.

11. Smith, R. C.: Job Attitudes of Air Traffic Controllers : A Comparison of Three Air Traffic Control Special ties. FAA Office of Aviation Medicine Report No. AM-73-2, 1973.

12. Chiles W D and G. West: Multiple Task Performance as a Predictor of the Potential of Air Traffic Controller Trainees: A Followup Study. FAA Offic of Ariation Medicine Report No. AM-74-10, 1974 

Air Traffic Control Trainee Questionnaire

Name

Birth Date

A. In terms of your job as an FAA-ATC, please indicate whether you "Agree" or "Disagree" with each statement listed below by placing an "X" In the approprlate column. Be sure to check either an "Agree" or "Disagree" response for each statement.

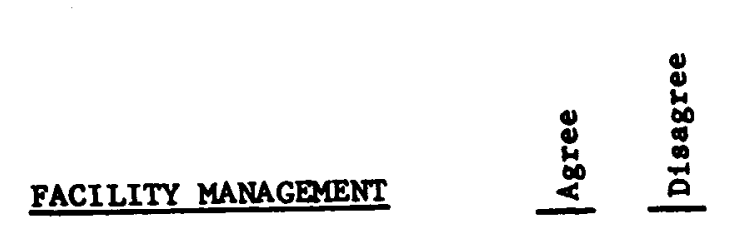

Concerned ...............

Cold......

Informed.

Regimented...

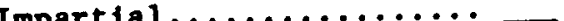

Good planning...........

Suffictently capable..... = -

Too bureaucratic......... -

Gave too few benefits..... - -

Provided good training.... - -

Inflexible.............. -

Dympathetinated against me.. - -

Trled to protect me

too much............... -

Treated me as different.

Set different standards
of achlevement for me...

\section{CO-WORKERS}

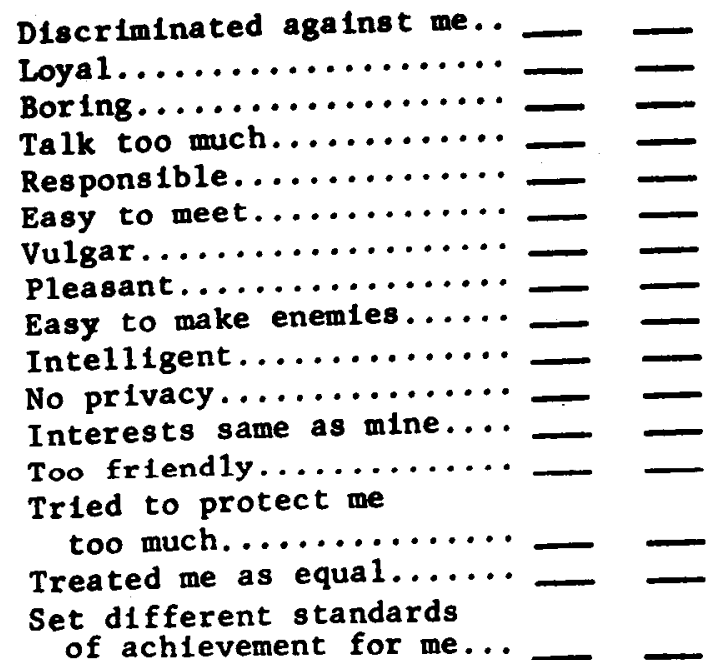

SUPERVISION

Helpful................ -

Hard to please........... -

Praised good work........ - -

Tactful...............

Annoy Ing ...............

Stubborn................

Intelligent............

Too little supervision.... - -

Quick tempered........... -

Told me where I stood..... - -

knew job well........... -

Discriminated against me.. -

Tried to protect me

Tried to protect we

too much............... -

Treated me the same as

others................ -

Set different standards

of achlevement for me... _ - -

\section{WORK ITSELF}

Good job security........ - -

Fascinatiny...........

Rout Ine..................

Useful .................

Frustrating.............

plessant

Challeng1ng............

Chad for heal th...........

Sense of accomplishment... $=$

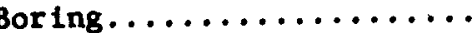

Fatiguing.................

Easler than I expected.... - -

Responsibility too great.. - -

No chance for personal 
APPENDIX A-Cont.

\begin{tabular}{|c|c|c|c|}
\hline ENTRY-LEVEL PAY & 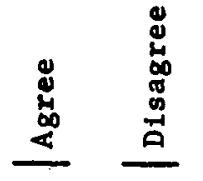 & ASSIGMMENTS & 怤 \\
\hline 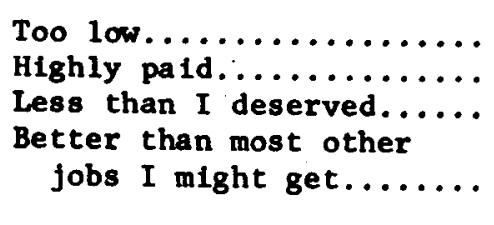 & $=\bar{z}$ & $\begin{array}{l}\text { Facility I wanted...... } \\
\text { Based on ability } \ldots \ldots \ldots \\
\text { Option I wanted........ } \\
\text { Good opportunity to } \\
\text { transfer................. }\end{array}$ & 二 \\
\hline FACILITY TRAINING & & PROMOTIONS & \\
\hline 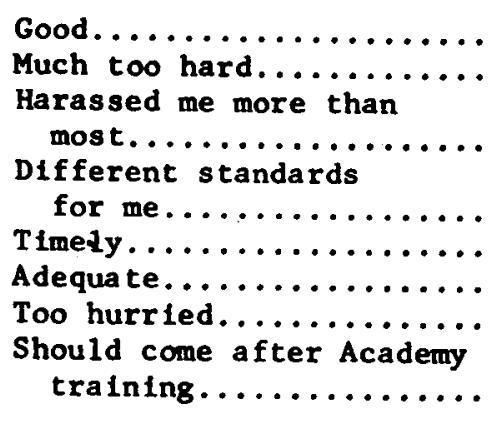 & $\begin{array}{l}=- \\
= \\
=\end{array}$ & 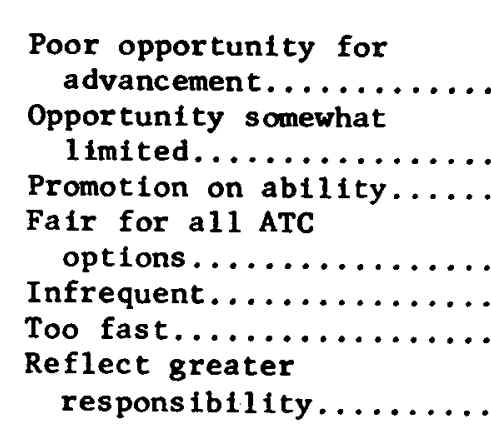 & $\begin{array}{l}\bar{z} \\
\bar{z}\end{array}$ \\
\hline WORKING CONDITIONS & & SHIFT WORK & \\
\hline 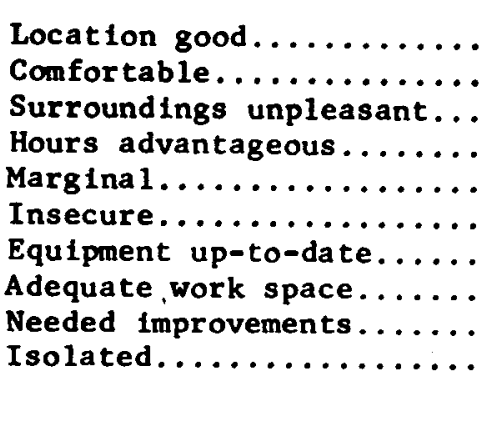 & $\begin{array}{l}= \pm \\
= \\
= \\
=\end{array}$ & 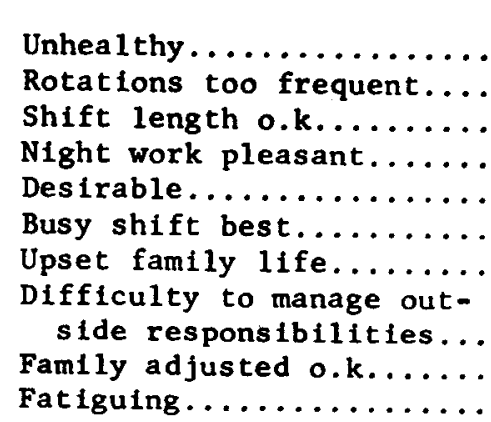 & $\begin{array}{l}E \\
z \\
\end{array}$ \\
\hline
\end{tabular}

B. Please complete the following statements. If there is not sufficient space for your response, you may continue on the reverse side of this

The best feature of being an FAA air traffic controller is

The worst feature of being an FAA air traffic controller is 
C. Check the adfective which best describes your FM-ATC experience.

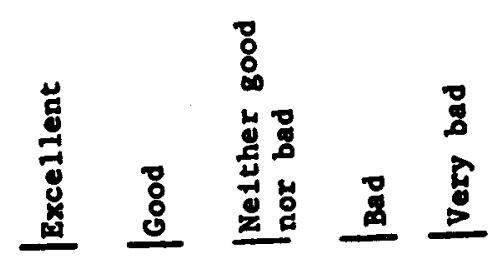

a. When I accepted appointment as an ATC, wy information about ATC job duties was............... -

b. When I accepted appointment as an ATC, my Information about how and when I might be.................. - - - - - eliminated from training was..........

c. When I accepted appointwent as an ATC, my Information about ATC career progression

d. When I accepted appointment as an ATC, my to non-ATC jobs was.............................

e. The training at the PAM Academy ma................ - - - - - - -

f. The training at my facility was................... - - - - - -

8. The training ability of FM Acadewy Inetructors was.. - - - - - -

h. The tralning ability of facility instructors was.. - - - - - -

1. The ability of FM Academy Inatructors to deternine Thich trainees vere likely to be good, and which which trainees were 11kely to ATC work was............. - - - - - were 11 kely to be poor, at ATC work was............

As a result of PMA Academy training, wy understanding of ATC work and ablilty to apply that understanding was.

k. As a result of facility training, wy understanding of ATC work and wy ability to apply that understanding was............................ - - - - -

D. Please complete the following statements. If there is not sufficient D. Please complete the following stacentinue on the reverse side of this space

If I could make two changes in the total ATC system, I would recoumend:

(1)

(2) 
APPENDIX A-Cont.

E. For each question 11sted below, check the one phrase which best describes your answer.

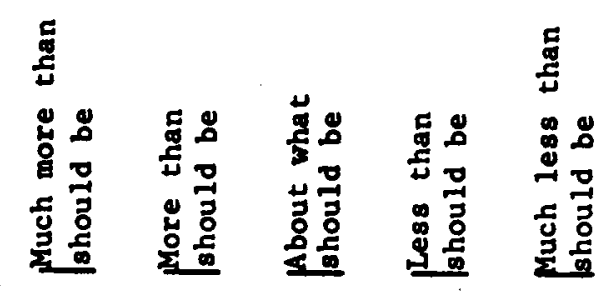

(a) How much in terms of job duties do supervisors or crew chlefs expect of new trainee and developmental controllers in general?

(b) How much in terms of job duties do supervisors or crew chiefs expect of new trainee and developmental controllers

(c) How much in terms of job duties do supervisors or crew chiefs expect of who are from minority groups?........

(d) How much in terms of job duties do supervisors or crew chiefs expect of new trainee and developmental controllers

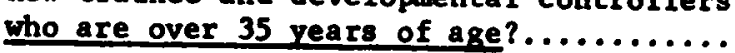

2.

(a) How much in terms of job duties do journeyman controllers expect of new trainee and developmental controllers

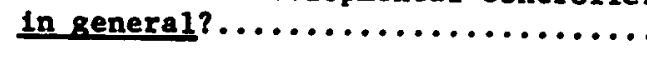

(b) How much in terms of fob duties do journeyman controllers expect of new trainee and developmental controllers who are females?.

(c) How much in terms of job duties do Journeyman controllers expect of new trainee and developmental controllers who are from minority groups?........

(d) How much in terms of job dutles do journeyman controllers expect of new trainee and developmental controllers who are over 35 years of age?

8
8
7
0
0
0

$\ldots \ldots \ldots$

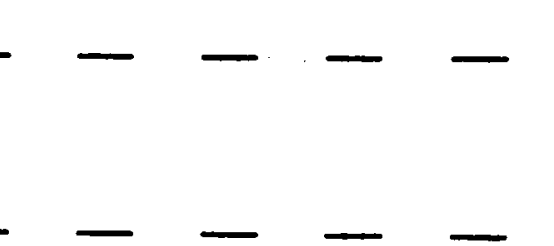


(a) How do journeyman controllers accept new trainee and developmental controllera

(b) How do journeyman controllers accept nev tralnee and developmental controllers tho are females?.............................. - tho are females?

(c) How do Journeyman controllers accept new trainee and developuental col

(d) How do Journeyman controllers accept new trainee and developmental controllers who are over 35 years of aze?.................. - - - -

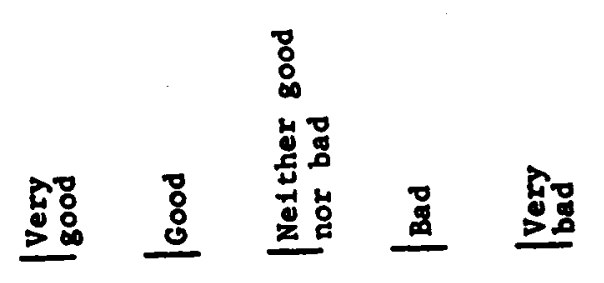

4.

(a) What kind of treatment do Journeyman controllers give new trainee and controllers in genere1?..........- - - - - - - - - -

(b) What kind of treatment do Journeyman controllers give new trainee and developmental controllers who are

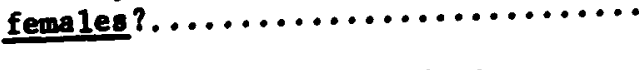

(c) What kind of treatment do journeyman controllers give new trainee and developmental controllers who are from minor ity groups? .......................... Journeyman

(d) What kind of treatment do jou and controllera controllers who are

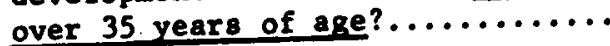




\section{APPENDIX A-Cont.}

F. Below is a list of possible reasons why some people leave the ir jobs. Only one reason may be important or several may contribute to leaving. Please rank those items which were most important in your leaving FAAATC work. You may rank as many as four items. please read through all of the items before you begin ranking.

If only one item was important, put a "l" in the space provided to the left of the item. If two items were important reasons, rank the most important reason " $l$ " and the second most important "2." Follow the same procedure if you want to rank three or four items, but rank no more than four. If you choose any items from $g$ through $t$, please complete the statement, circle alternatives, or give examples as

required. The last two items permit you to write in important reasons which may not be listed.

a. Disliked shift work.

b. Pay inadequate.

c. Lacked aptitude for job.

d. Poor working conditions in facility.

e. Too much responsibility in job

f. Discriminated against by co-workers, supervisors, management because of my age, race, sex. (Circle any appropriate underlined words.)

G. Failed training because

h. Health problems due to

i. Desired different geographic location because

j. Family problems because

k. Lack of motivation for job because

1. Little in common with co-workers because

m. Disliked treatment by co-workers: (example)

n. Disliked treatment by supervisors: (example)

o. Training was inadequate because

p. Got a job I considered better because

q. Found I didn't like this type of work because

r. Insecurity due to

s. Other: (specify)

t. Other: (specify) 


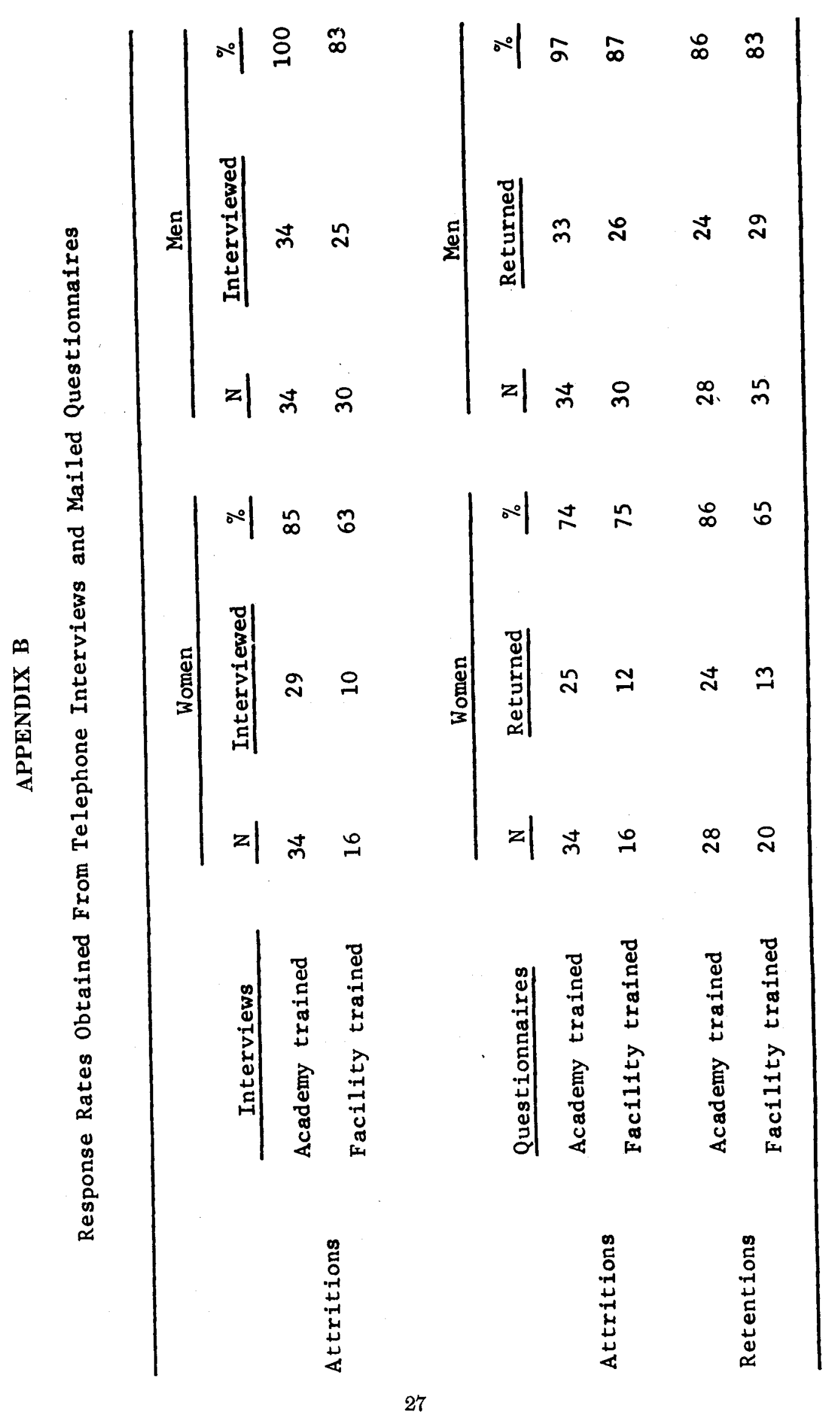




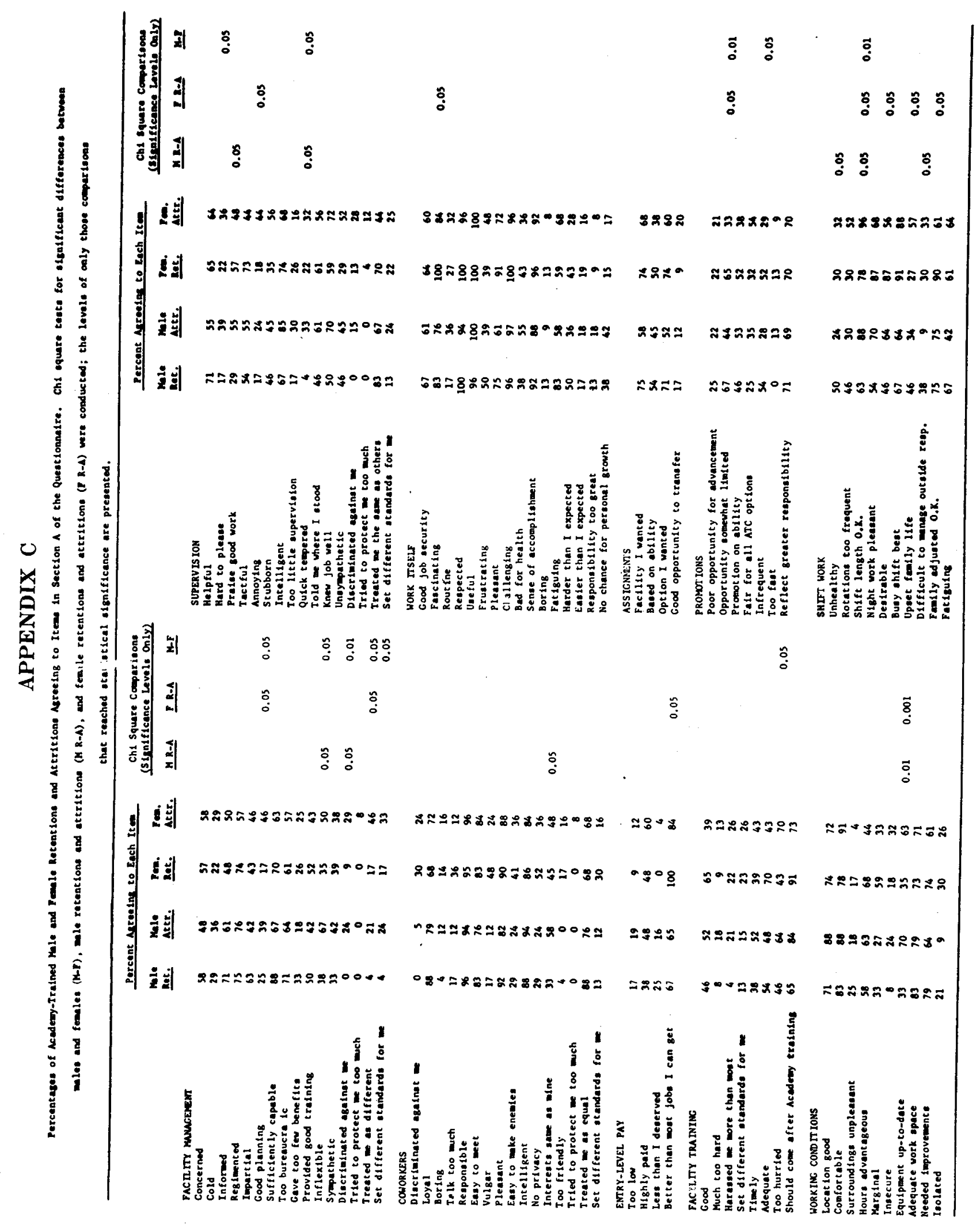

28 


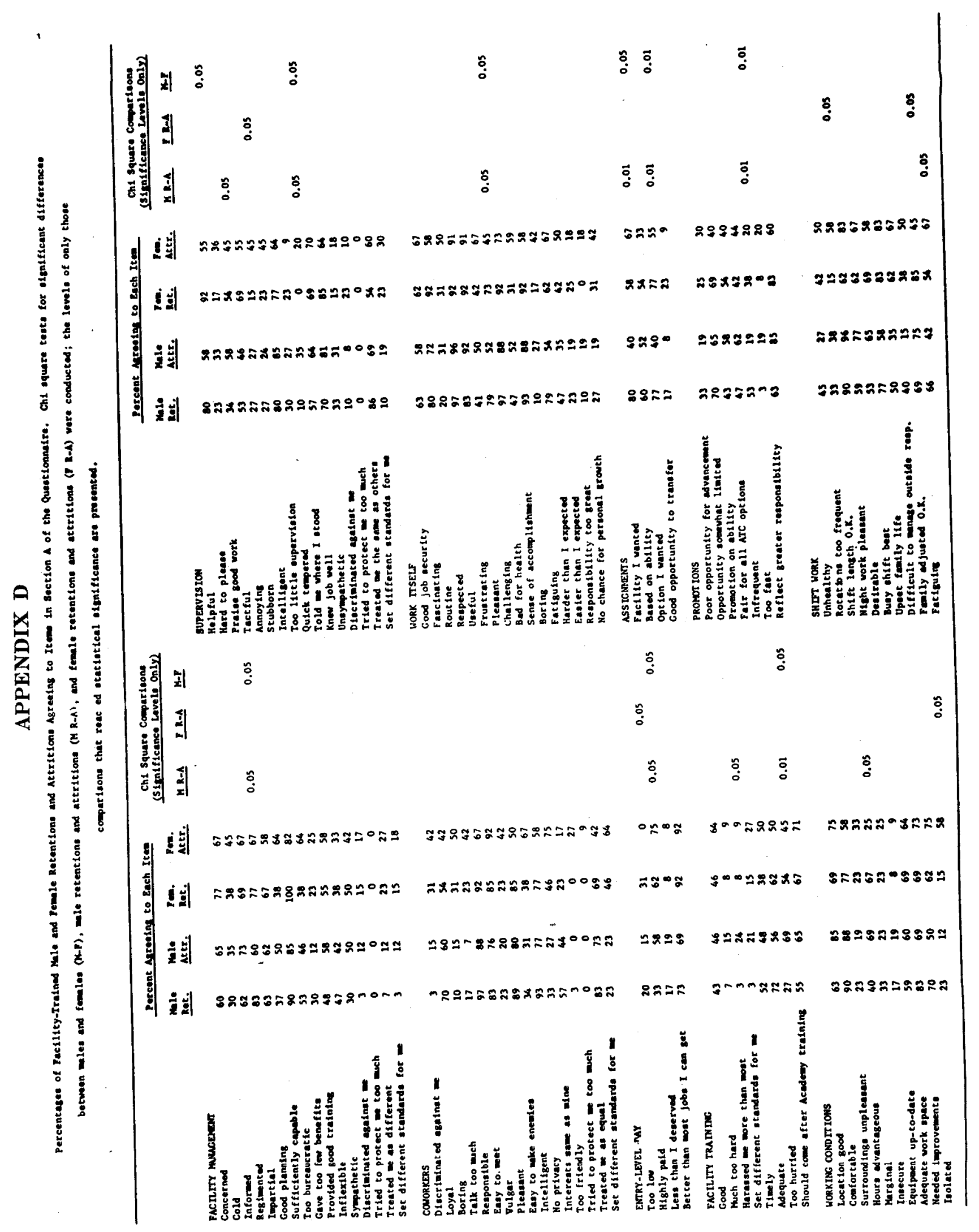




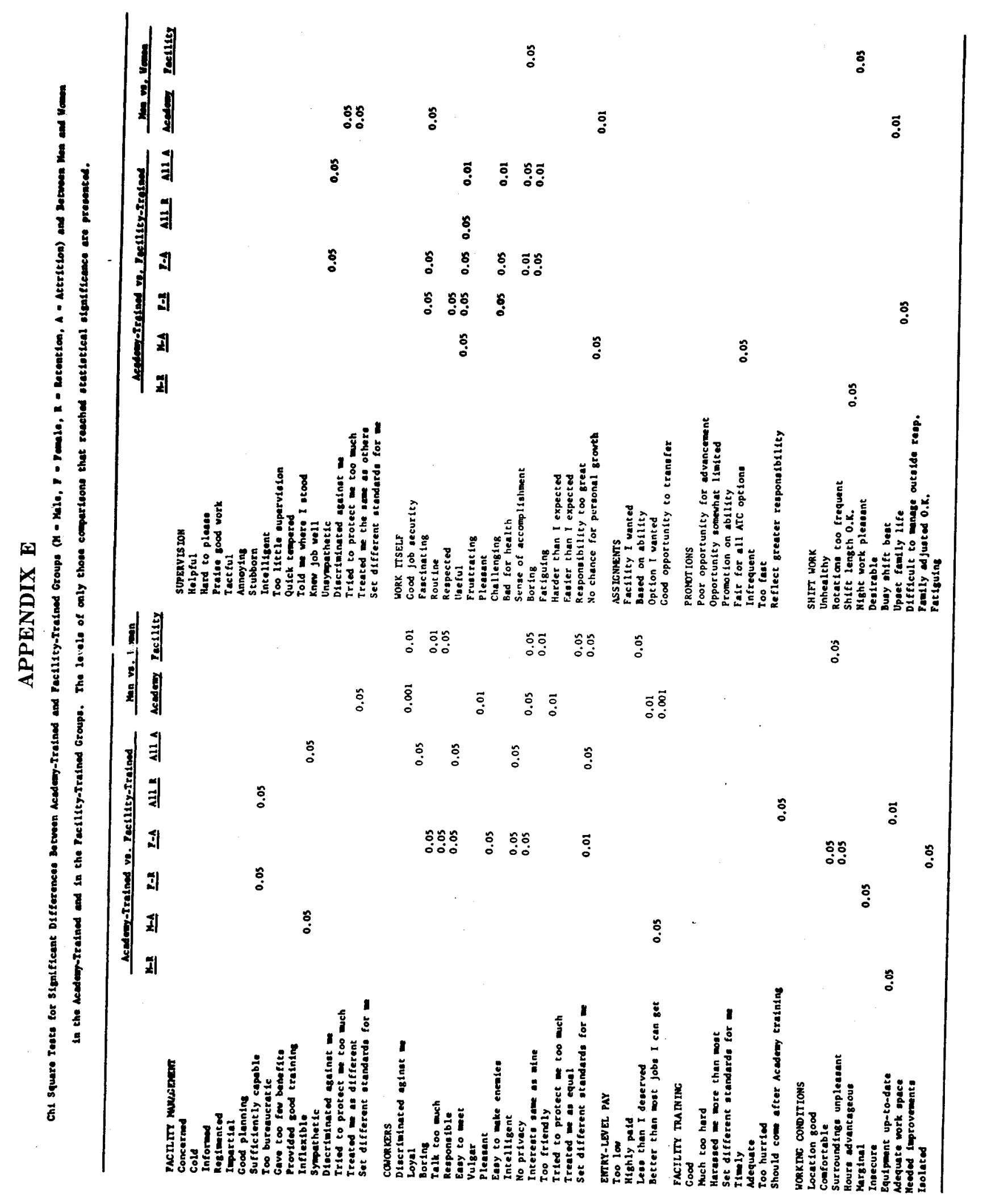

30 


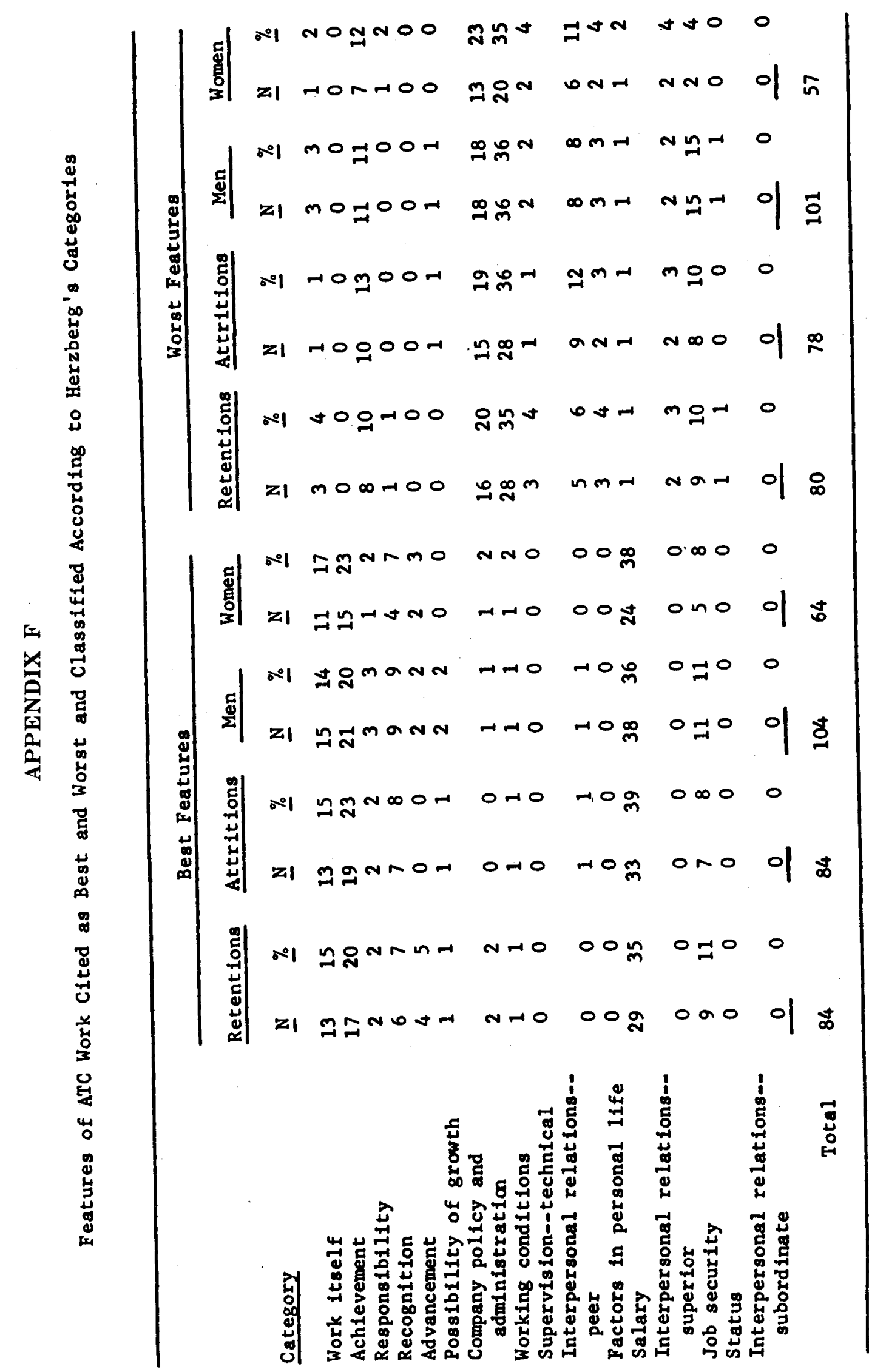

31 
APPENDIX G

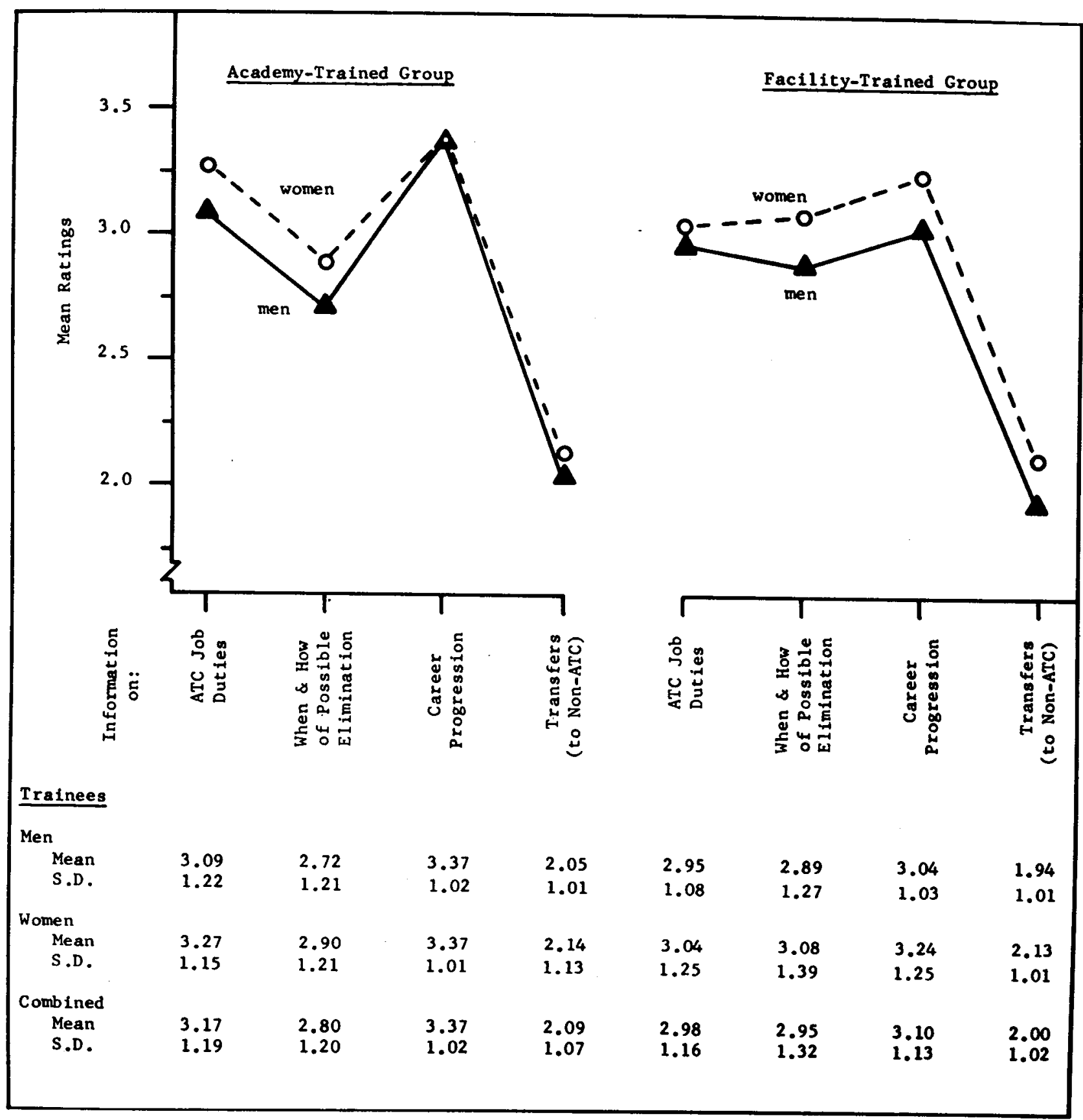

Appenmix G. Mean ratings by En Route male and female recruits regarding the quality of their information about the ATC career by the time of appointment (in response to Section $\mathrm{C}$ of the questionnaire). 


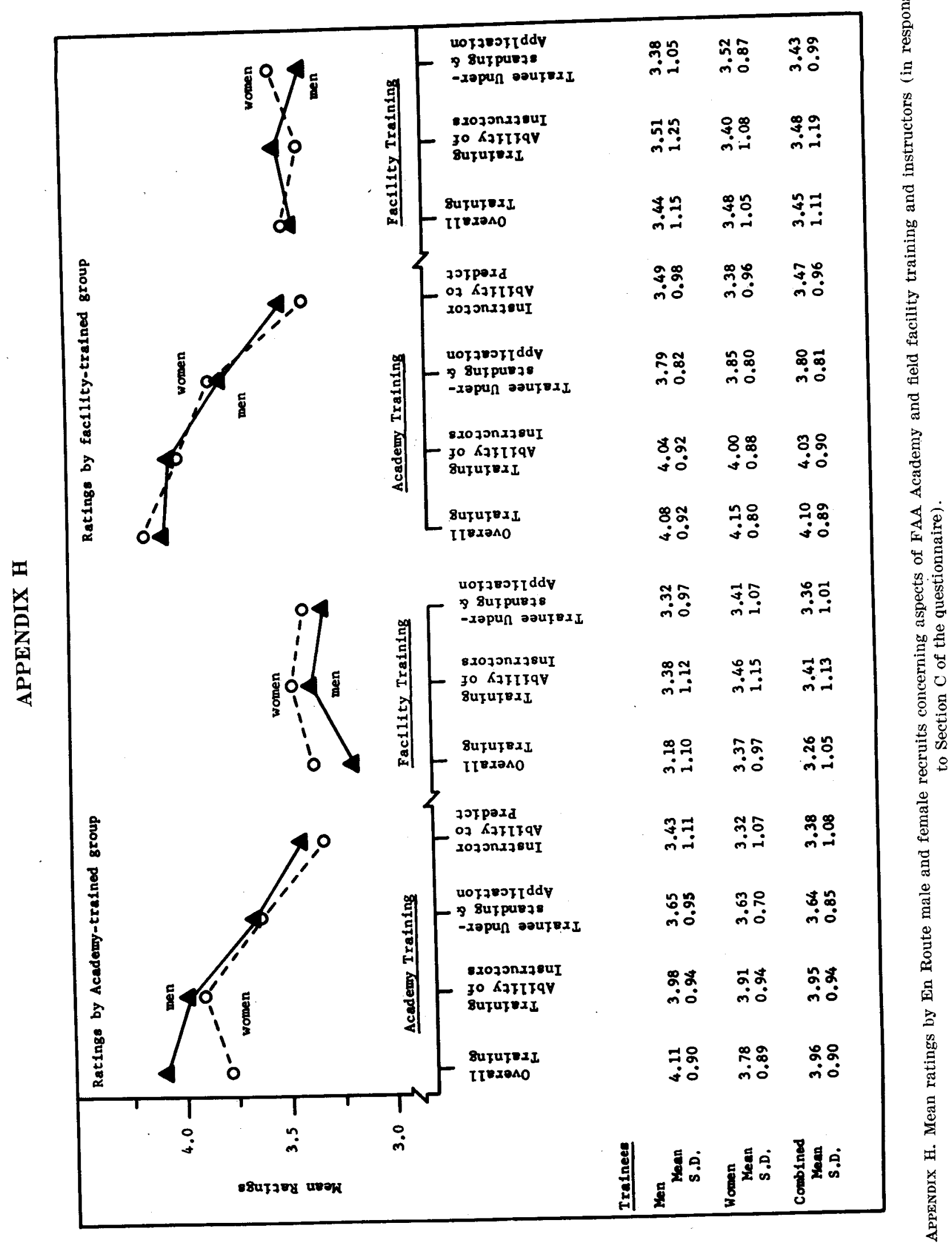




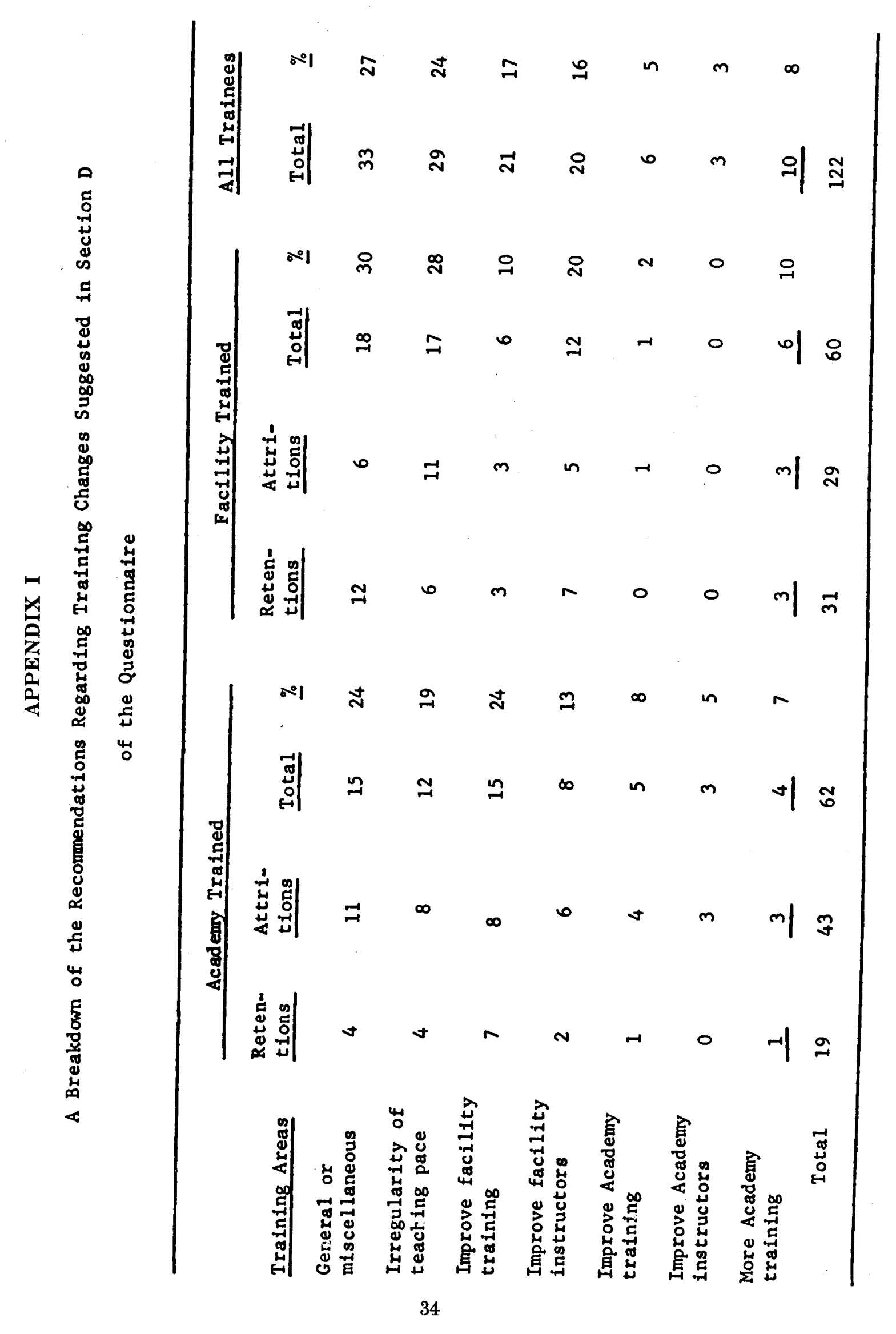




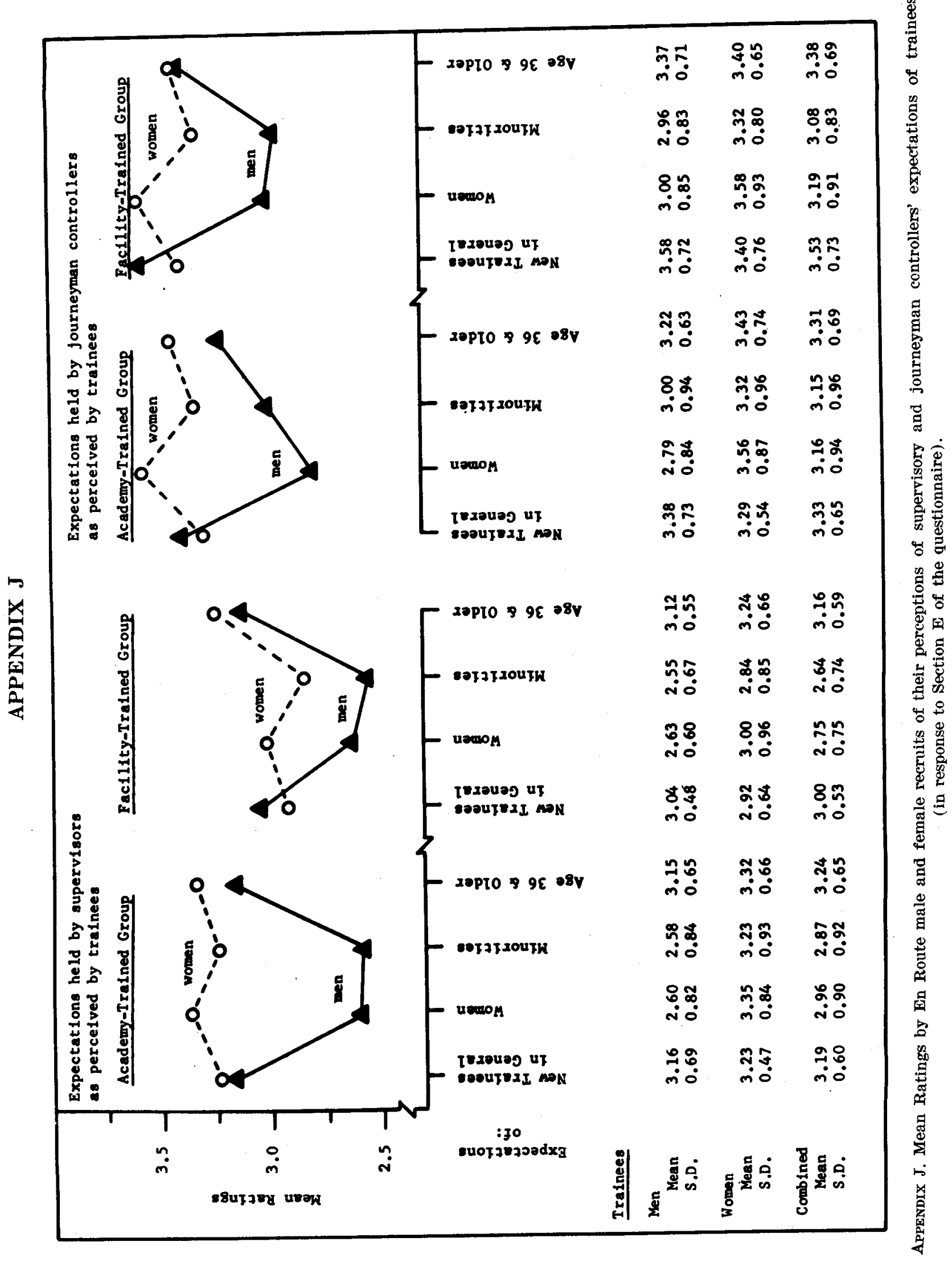




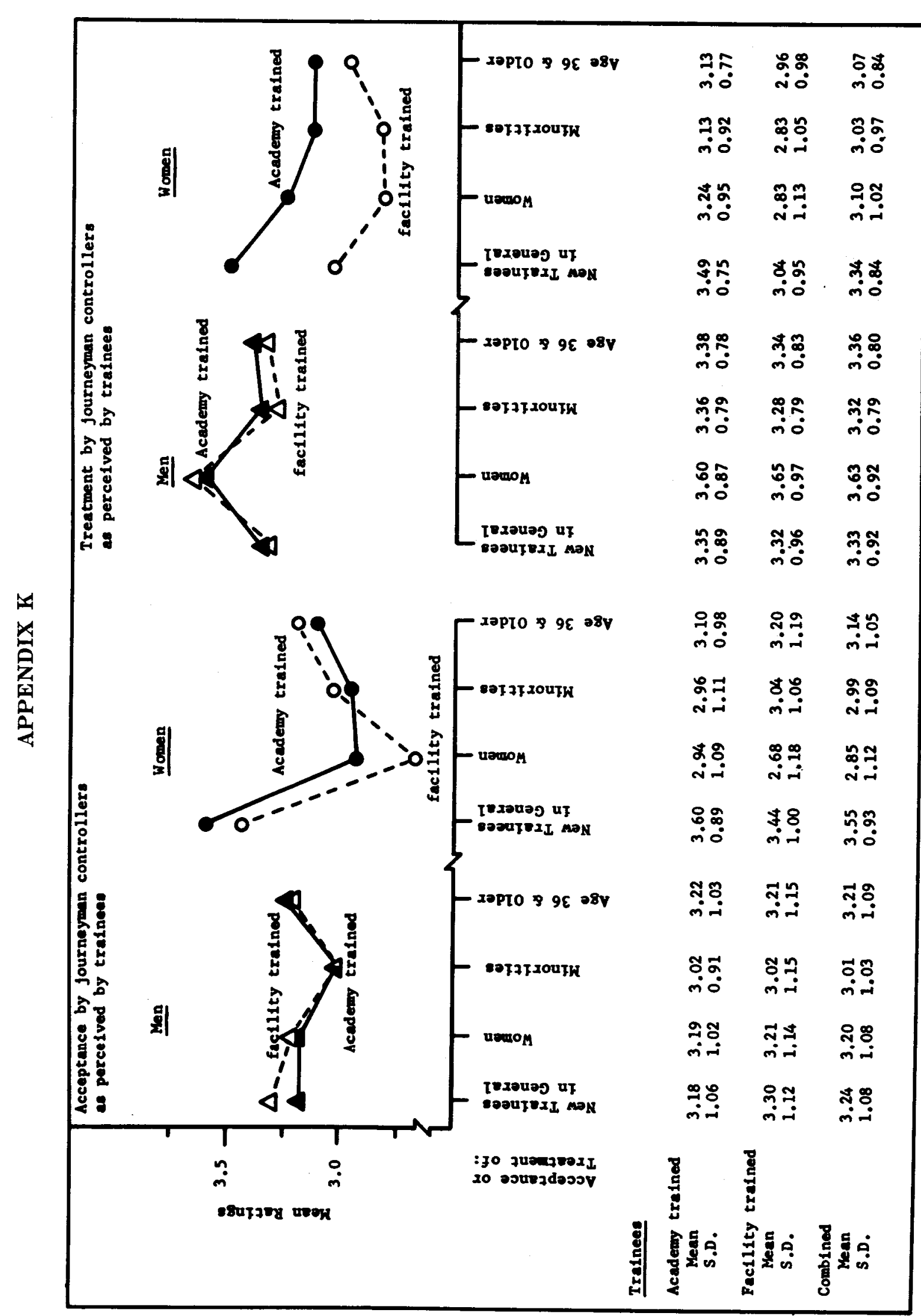



